\title{
O INDICADOR DE DESENVOLVIMENTO REGIONAL SUSTENTÁVEL NA REGIÃO SUL DO BRASIL'
}

\section{THE REGIONAL SUSTAINABLE DEVELOPMENT INDEX IN SOUTHERN BRAZIL}

\author{
Tatiani Sobrinho Del Bianco \\ Universidade Estadual do Oeste do Paraná - Toledo - PR - Brasil \\ Jandir Ferrera de Lima \\ Universidade Estadual do Oeste do Paraná - Toledo - PR - Brasil \\ Camilo Freddy Mendoza Morejon \\ Universidade Estadual do Oeste do Paraná - Toledo - PR - Brasil
}

\begin{abstract}
Resumo: Os indicadores de sustentabilidade fornecem elementos que auxiliam na avaliação do processo de desenvolvimento das regiões e também do cumprimento dos objetivos e metas para produzir simultaneamente bem-estar humano em sintonia com um ecossistema sustentável. Dito isso, o presente trabalho objetivou analisar o Desenvolvimento Regional Sustentável da Região Sul do Brasil, a partir da elaboração do Indicador de Desenvolvimento Regional Sustentável - (IDRS), que além das variáveis econômicas e sociais incorporou também variáveis ambientais. De forma geral, o IDRS da Região Sul do Brasil demonstrou que no ano 2000 havia 95.5\% dos municípios em transição e $4.45 \%$ em estágio retardatário. Já em 2010 , havia $99.2 \%$ dos municípios em transição e $0.67 \%$ em estágio retardatário. Desse modo, conclui-se que apenas $0.08 \%$ dos municípios estudados ficaram classificados como em estágio avançado, em ambos os anos analisados. O bom IDRS da Região Sul do Brasil foi consequência do desempenho da variável emprego formal, consumo de energia elétrica setorial residencial, despesas com saúde, educação, desporto, lazer, previdência e assistência, estabelecimentos com áreas de matas naturais e artificiais, área verde por habitante e risco da moradia. Dessa forma, esses dados se constituem num instrumento otimizado para o planejamento de políticas públicas e ações em prol do desenvolvimento sustentável em escala regional, estadual e municipal.
\end{abstract}

1 Este artigo apresenta resultados parciais de pesquisa financiada com recursos do Conselho Nacional de Desenvolvimento Cientifico e Tecnológico - CNPQ e Fundação Araucária - PR. 
Palavras-chave: Desenvolvimento sustentável. Economia regional. Desenvolvimento regional.

Abstract: The sustainability indicators provide elements that facilitate the assessment of progress in the regions and also the fulfillment of the objectives / goals to produce human well-being both in line with a sustainable ecosystem. Thus, this paper analyzes the Sustainable Regional Development of the Southern region of Brazil, from the preparation of Sustainable Development Indicator (IDRS), which in addition to economic and social variables incorporates environmental variables. In 2010, there were $99.2 \%$ of the municipalities in transition and $0.67 \%$ in laggard stage. Thus, it is concluded that only 0:08\% of the municipalities studied were classified as advanced stage in both years analyzed. The IDRS of southern Brazil was a result of the performance of the variable formal employment sector electricity consumption, residential energy consumption, expenditure on health, education, sports, leisure, welfare and assistance, properties and areas of natural and artificial forests, green area per inhabitant and risk of housing. The result of IDRS in southern Brazil showed that in 2000 there were $95.5 \%$ of the municipalities in transition and $4.45 \%$ in laggard stage. Thus, these data represent an optimized tool for the design of public policies and actions for sustainable development in regional, state and municipal.

Keywords: Sustainable development. Regional economy. Regional development.

\section{Introdução}

Entre 2000 e 2010, em relação à média brasileira, na Região Sul do Brasil prevaleceu o crescimento econômico, mas, no que se refere às condições de vida da população, não houve muitas melhorias. É certo que as melhorias em termos de emprego e renda tendem a fortalecer a longevidade, pois garantem às famílias melhores condições no poder de compra, porém, se não houver melhorias na produtividade, esses ganhos tendem a desaparecer no longo prazo (RAIHER \& FERRERA DE LIMA, 2014).

A análise dos dados sobre o nível de desenvolvimento humano da Região Sul do Brasil revelou a necessidade de se pensar em políticas de desenvolvimento regional com inclusão social, pois, regionalmente, ainda persistem desigualdades socioeconômicas.

No entanto, os indicadores de desempenho não devem apenas ser baseados nas variáveis econômicas e sociais, pois esses indicadores devem também contemplar as variáveis relacionadas com o meio ambiente. Nesse contexto, no presente trabalho apresenta-se um indicador de sustentabilidade, com base nos aspectos sociais, 
econômicos e ambientais, possibilitando uma avaliação completa do local analisado e, assim, identificar o perfil de desenvolvimento sustentável da Região Sul do Brasil.

Assim, os indicadores de sustentabilidade, formulados para usuários específicos, constituem um sistema de informações que permite que as regiões avaliem seu progresso no que diz respeito à questão ambiental, social e econômica, nos moldes do desenvolvimento sustentável. Dessa forma, os indicadores de sustentabilidade tornam-se também instrumentos para a elaboração de políticas públicas (MARTÍNEZ, 2004).

A partir desse cenário, o presente estudo objetivou analisar o Desenvolvimento Regional Sustentável da Região Sul do Brasil, a partir da elaboração do IDRS, que além das variáveis econômicas e sociais incorporou também variáveis ambientais². Para tanto, a construção do indicador de sustentabilidade da Região Sul do Brasil considerou a análise específica dos indicadores parciais inerente aos cálculos das 30 variáveis econômicas, sociais e ambientais, correspondentes ao período de 2000 e 2010.

\section{Indicadores de Sustentabilidade}

Antes da revisão bibliográfica acerca dos indicadores de sustentabilidade é preciso apresentar uma breve contextualização sobre o conceito, modernamente descrito como desenvolvimento sustentável. Embora não haja um termo universalmente aceito, alguns autores, como Ignacy Sachs, Ademar Ribeiro Romeiro, entre outros, buscam apresentar uma definição cientifica para o mesmo.

De acordo com Romeiro (2003), o conceito de desenvolvimento sustentável é normativo e surgiu com o termo ecodesenvolvimento, no início da década de 1970, em meio a um contexto de controvérsias sobre a relação entre crescimento econômico e meio ambiente, exacerbado, principalmente pela publicação do "Relatório do Clube de Roma", em 1972.

2 Esse texto é uma versão dos resultados de pesquisa financiada pela Fundação Araucária (PR) e pelo Conselho Nacional de Desenvolvimento Cientifico e Tecnológico CNPQ. 
Autores como Sachs $(2008,2009)$, defendem que a transição para o desenvolvimento sustentável se faz a partir do gerenciamento de crises, partindo de uma mudança imediata de paradigma, passando do crescimento financiado pelo uso de recursos externos (importados) para um crescimento baseado na mobilização de recursos internos. Assim, a crítica ao crescimento selvagem e seus impactos sociais e ambientais estimulam uma extensa literatura e formulação de importantes conceitos. Dessa forma, quer seja denominado como ecodesenvolvimento ou desenvolvimento sustentável, a abordagem fundamentada na harmonização entre características sociais, econômicas e ambientais se faz válida desde a Conferência de Estocolmo, em 1972, e segue pautada nos oito critérios da sustentabilidade parcial, sendo eles: social, cultural, ecológico, ambiental, territorial, econômico, política nacional e política internacional.

Dito isso, o monitoramento e avaliação de impactos ambientais, bem como a sua contabilização econômica, tornaram-se uma exigência. No entanto, existe a preocupação com a questão de se saber até que ponto os setores das atividades comprometem a preservação de equilíbrios socioambientais fundamentais, preocupação que se traduz na elaboração de indicadores de sustentabilidade (ROMEIRO, 2004).

No campo do desenvolvimento sustentável, um indicador adequado, além de uma estatística, que define o comportamento de uma região deve também agregar, ou mesmo simplificar, as informações relevantes, tornando-as perceptíveis e quantificáveis. Assim, os indicadores de sustentabilidade fornecem elementos que facilitam a avaliação do progresso das regiões e também do cumprimento dos objetivos/metas de curto, médio e longo prazo para produzir simultaneamente bem-estar humano em sintonia com um ecossistema sustentável (MARTíNEZ, 2004).

Uma das mais importantes contribuições quanto ao uso de indicadores de sustentabilidade foi o desenvolvimento do índice denominado "Pegada Ecológica". A metodologia original consistia em construir uma matriz de consumo/uso de terra, considerando cinco categorias principais de consumo (alimento, moradia, transporte, bens de consumo e serviços) e seis categorias principais do uso da terra (energia da terra, ambiente (degradado) construído, jardins, terra fértil, 
pasto e floresta sob controle), cujo objetivo era calcular a área de terra necessária para a produção e a manutenção de bens e serviços consumidos por uma determinada comunidade (SICHE et al., 2007).

Outro indicador, considerado de grande importância na discussão sobre sustentabilidade de países, é o Índice de Sustentabilidade Ambiental. Esse indicador envolve cinco dimensões: sistemas ambientais, estresses, vulnerabilidade humana, capacidade social e institucional e responsabilidade global (SICHE et al.,2007; VEIGA, 2009). Siche et al. (2007) apresentam estudos, nos quais os chamados Indicadores de Desempenho Emergético ou EMPIs (do inglês Emergy Performance Index), Renovabilidade e Índice de Sustentabilidade consideram o sistema econômico como um sistema termodinâmico aberto, e contabilizam os fluxos dos recursos da economia em unidades de energia agregada. Estes índices estão baseados na teoria da emergia proposta por Odum em 1996. Os autores ainda apresentam que estudos e propostas para avaliar a sustentabilidade em nível global e de países, foram e tem sido realizada utilizando a análise emergética como ferramenta, conforme elencados nos trabalhos de Brown \& Ulgiati, 199; Ulgiati et al., 1994; Brown; McClanaham, 1996; Siche \& Ortega, 2005; 2006.

De acordo com Guimarães e Feichas (2009), os indicadores são um conjunto de sinais que facilitam a avaliação do progresso de uma determinada região na busca pelo desenvolvimento sustentável, sendo ferramentas cruciais no processo de identificação de problemas, formulação de políticas, implementação e avaliação das mesmas. Em síntese, para que indicadores sejam instrumentos de um processo de mudança rumo ao conceito de desenvolvimento sustentável, eles devem congregar características que permitam: mensurar diferentes dimensões de forma a apreender a complexidade dos fenômenos sociais; possibilitar a participação da sociedade no processo de definição do desenvolvimento; comunicar tendências, subsidiando o processo de tomada de decisões; e relacionar variáveis, para obter-se dados mais condizentes com a realidade mutável com que nos deparamos.

\section{Metodologia}


A partir do levantamento bibliográfico acerca dos indicadores de sustentabilidade, este trabalho utilizou como base metodológica os estudos regionais, compostos pelo Indicador de Desenvolvimento Regional (IDR) proposto por Gualda (1995; 2003), Oliveira (2005), Ferrera de Lima et al. (2011) e Rodrigues \& Ferrera de Lima (2013), os quais foram adaptados para elaborar o IDRS.

Com relação ao levantamento dos dados, essa pesquisa se caracterizou como exploratória e descritiva, pois buscou a compreensão de fenômenos sociais, econômicos e ambientais a partir da localização, avaliação e síntese dos dados e informações em determinado período de tempo e espaço. Os dados foram coletados no Instituto Brasileiro de Geografia e Estatística - IBGE, na base de dados do Instituto de Pesquisa Econômica Aplicada - IPEADATA, Instituto Paranaense de Desenvolvimento Econômico e Social - IPARDES, Programa das Nações Unidas para o Desenvolvimento - PNUD e Relação Anual de Informações Sociais - RAIS do Ministério do Trabalho. O elemento de estudo concentrou-se nos 1.190 municípios da Região Sul do Brasil, correspondente aos anos de 2000 e 2010. A escolha de dois períodos distintos permitiu avaliar o comportamento e suas respectivas modificações. Isso posto, a estimativa do IDRS utilizou as variáveis descritas nos Quadros 1, 2 e 3, em anexo.

Com base na escolha das variáveis, estimou-se o IDRS a partir dos indicadores parciais: econômico, social e ambiental. As equações que compõem o indicador foram extraídas, adaptadas e ampliadas de Rodrigues e Ferrera de Lima (2013, p.185). O indicador parcial econômico (IEi), comporta variáveis que descrevem a situação econômica dos municípios da Região Sul do Brasil, permitindo apontar as condições que as regiões possuem de gerar investimentos em: infraestrutura, saúde, educação, pesquisa e desenvolvimento, geração de emprego e a preservação dos recursos naturais, conforme apresentado na Equação 01 .

$I E i=(I E F+I I C M S+I F P M+I D O T+I C E S+I P I B P C+I V A+I V E C+I S E F+$ IROT) $* P$

Em que: IEi é o Indicador parcial econômico; IEF é o Índice do emprego formal do município i; IICMS é o Índice do ICMS do município i; IFPM é o Índice do Fundo de Participação do Munícipio do Estado i; IDOT é o Índice das Despesas Orçamentárias do Municipio no Estado i; 
ICES é o Índice do Consumo de Energia Setorial do município i no Estado i; IPIBpc é o Índice do PIB per capita do município i no Estado i; IVA é o Índice do Valor Adicionado do Município i no Estado i; IVEC é o Índice da Vitalidade da Economia no Município i no Estado i; ISEF é o Índice do Saldo Migratório de Emprego no Município i no Estado i; IROT é o Índice da Receita Orçamentária do Município i no Estado i; e P é o Participação da variável Wi do Município i.

O indicador parcial social (ISi) apresentado na Equação 02, indica, mediante uma série de variáveis, o perfil do desenvolvimento social de cada mesorregião.

$I S i=(I P U+I P R+I T E F E F+I C E R+I D S S+I D A P+I D E C+I D D L+I M F+$ $I I D H M) * P$

Em que: ISi é o Indicador parcial social; IPU é o Índice da população urbana do município i; IPR é o Índice da população rural do município i; ITEFEF é o Índice da Taxa de Frequência do Ensino Fundamental do município i; ICER é o Índice de consumo de energia elétrica residencial do município i; IDSS é o Índice de despesa com saúde e saneamento do município i; IDAP é o Índice de despesa com assistência social e Previdência do município i; IDEC é o Índice de despesa com educação e cultura do município i; IDDL é o Índice de despesa com desporto e lazer do município i; IMF é o Índice de Mortalidade infantil do município i; IIDHM é o Índice do Indicador de Desenvolvimento Humano do município i; P é o Participação da variável Wi do município i.

O indicador parcial ambiental (IAi) apresentado na Equação 03, contém variáveis que definem a situação do meio ambiente regional. A análise dos indicadores parciais é fundamental para destacar as particularidades e gargalos municipais e revelar fatores que devem ser melhorados para que as regiões tenham níveis avançados de desenvolvimento sustentável.

$$
\begin{gathered}
I A i=(I S+I E F M+I P H+I A E+I A E B+I D D D+I R M+I D C L+I A V+I G R S) \\
* P
\end{gathered}
$$

Em que: IAi é o Indicador parcial ambiental; IS é o Índice da produção de silvicultura do município i; IEFM é o Índice de estabelecimentos com florestas e matas naturais e artificiais do município i; IPH é o Índice da poluição hídrica do município i; IAE é o Índice de abastecimento de água encanada no município i; IAEB é o 
Índice de abastecimento de agua encanada e banheiro no município i; $I D D D$ é o Índice de densidade demográfica (Maior que 2) dos domicílios no município i; IRM é o Índice de Risco das moradias inadequadas no município i; $I D C L$ é o Índice de domicílios com coleta de lixo no município i; IAV é o Índice de Área Verde por habitante no município i; IGRSU é o Índice de geração de $R S U$ no município i; e P é o Participação da variável Wi do município i.

O índice de participação da variável Wi do município " $i$ " $(P)$ e o índice da variável Wi do município "i" (IPWI) foram estimados por meio das Equações (04) e (05).

$$
P=\frac{W_{i}}{\sum_{i=1.191}^{j} W i}
$$

Em que: $\quad W i$ é o valor da variável no município, e, $\Sigma$ Wi corresponde ao valor total do Estado.

$I P W_{i}=\frac{W_{i-W_{\min }}}{W_{\max .}-W_{\min } .}$

Em que: IPWi é o índice da variável $W$ do município $i$; Wi $a$ participação da variável $W$ do município $i$; Wmin fator que corresponde à participação do município com o menor valor; e, Wmax é a participação do município com o maior valor.

Após as estimativas, o IDRS é calculado conforme os resultados das Equações (01), (02) e (03) estabelecendo os seus respectivos pesos, de acordo com a Equação (06):

$$
I D R S i=(I E i * 0.33)+(I S i * 0.33)+(I A i * 0.33)
$$

Considerando os resultados da Equação (6), o IDRS é classificado em três categorias que representam o estágio de desenvolvimento sustentável dos municípios. No Quadro 1, é apresentada a classificação do IDRS.

Quadro 1. Classificação do Indicador de Desenvolvimento Regional Sustentável (IDRS)

\begin{tabular}{|l|l|}
\hline IDRS $\geq 0,50$ & Avançado \\
\hline $0,10 \leq$ IDRS $\leq 0,49$ & Em transição \\
\hline IDRS $\leq 0.099$ & Retardatário \\
\hline
\end{tabular}


Fonte: adaptado de Gualda (1995; 2003); Ferrera de Lima et al. (2011); Rodrigues e Ferrera de Lima (2013).

Pela classificação proposta no Quadro 1, os municípios que apresentaram IDR superior a 0.50 foram considerados em estágio avançado, ou seja, apresentam uma dinâmica suficiente da sua base produtiva com avanços econômicos, sociais e ambientais. Os municípios que apresentaram IDRS entre 0.10 e 0.49 foram classificados como em transição, ou seja, apresentam uma estrutura econômica, social e ambiental em evolução que faz com que sua dinâmica de sustentabilidade seja menor que os municípios avançados. Os municípios com IDRS abaixo de 0.099 foram considerados como em estágio retardatário, pois encontram dificuldades em atrair e reter recursos, o que dificulta seu processo de desenvolvimento socioeconômico e sustentável (GUALDA, 1995; 2003; FERRERA DE LIMA et all, 2011 ; RODRIGUES \& FERRERA DE LIMA, 2013). 


\section{Indicador Econômico Parcial da Região Sul}

A análise dos resultados do indicador econômico dos 1.191 municípios da Região Sul do Brasil permitiu identificar que, no ano 2000, $0.25 \%$ do total de municípios foram classificados como em estágio avançado, $2.10 \%$ dos municípios como em estágio de transição e 97.6\% em estágio retardatário. No ano 2010, houve uma piora nos índices, pois evidenciou-se a redução do número de municípios classificados em estágio avançado, passando para $0.08 \%$ do total e, em transição, para $0.89 \%$. Consequentemente, na Região Sul do Brasil, cerca de $99 \%$ do total de municípios analisados ficou classificado como em estágio retardatário.

Na Figura 01 foi apresentada a amostra da dispersão dos valores do indicador econômico dos municípios da Região Sul do Brasil, representada pelos 45 maiores índices, durante os anos 2000 e 2010 . Analisando os dados, notou-se que a Região Sul possuía, no ano 2000, três municípios classificados em estágio avançado, sendo estes: Curitiba - PR (0.77), Joinville - SC e Porto Alegre - RS (0.53), e 25 municípios em estágio de transição, cabendo destaque para os cinco melhores índices obtidos nos municípios de Triunfo - RS (0.34), Blumenau - SC (0.29), Brusque - SC (0.23), Araucária - PR, Caxias do Sul - RS e Florianópolis SC (0.21). Os demais municípios (1.163) foram classificados em estágio retardatário. Cabe destacar que, dentre os municípios classificados em estágio retardatário, 596 apresentaram os piores índices para o indicador econômico, com valores menores que 0.01 , como foi o caso dos municípios de Westfália, São Pedro das Missões, Santa Margarida do Sul, Santa Cecília do Sul e Rolador, no Estado do Rio Grande do Sul, por exemplo.

Em 2010, ocorreu piora na classificação dos municípios da Região Sul do Brasil, pois, conforme demonstrado na Figura 1, houve retração quanto ao valor global do indicador econômico de todos os municípios analisados. Os municípios de Curitiba- PR, Joinville-SC e Porto AlegreRS apresentaram queda quanto ao valor final do indicador econômico, quando comparado com os resultados no ano 2000. O município de Curitiba - PR foi o único a permanecer em estágio avançado, embora tenha apresentado perda no valor final do índice econômico, passando de 0.77 , em 2000, para 0.64, em 2010. Os municípios de Joinville-SC e 
Porto Alegre- RS perdem representatividade no valor final do seu índice econômico e, em 2010, ficam classificados como em transição. 
Figura 1. Amostra da dispersão dos valores do Indicador Econômico da Região Sul do Brasil - 2000 - 2010

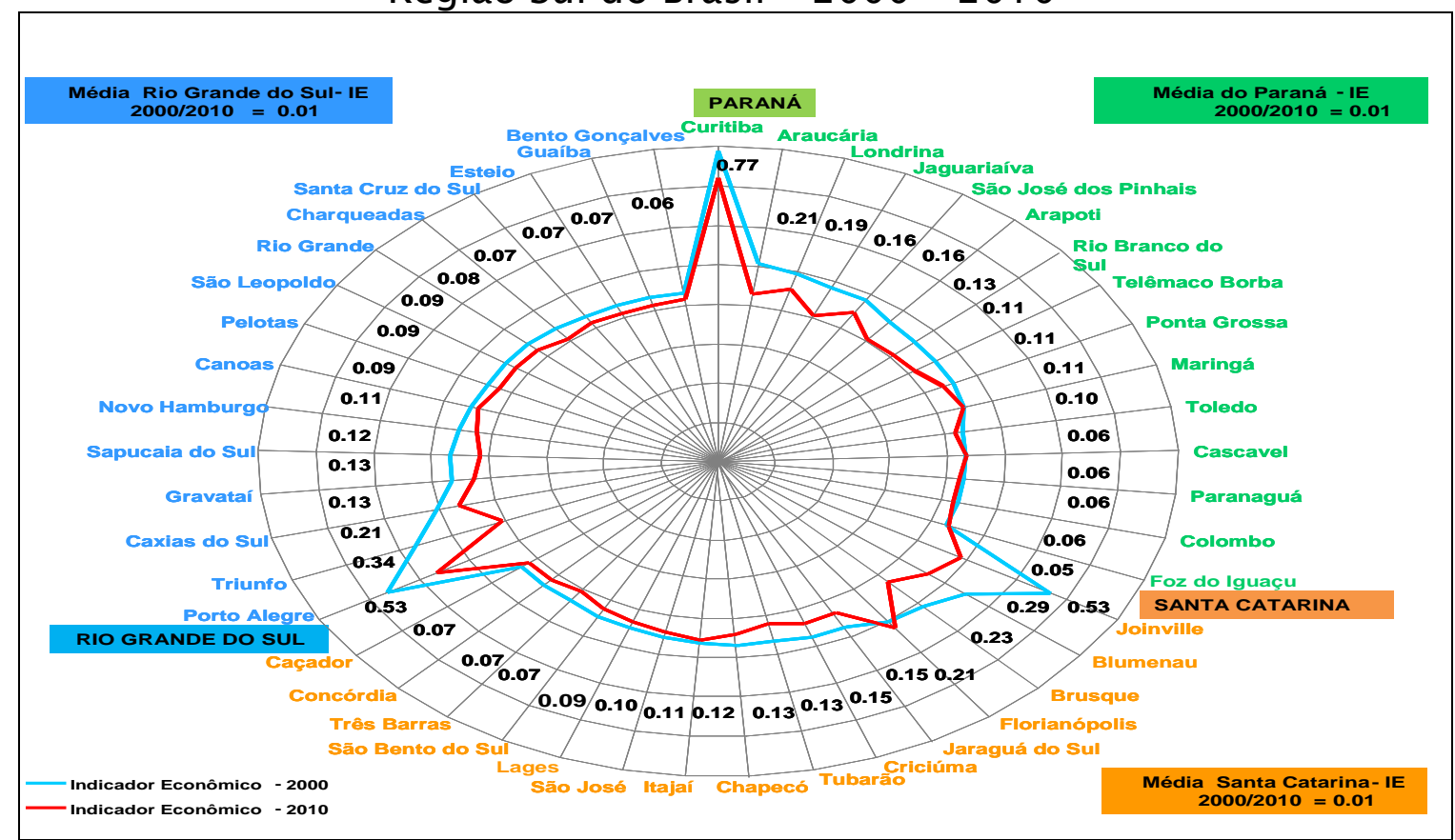

Fonte: Resultados da Pesquisa.

Houve também redução no número de municípios classificados como em transição, passando de 25 em 2000 para 10 em 2010, representando uma queda de $40 \%$. Os municípios em transição foram: Porto Alegre (0.33), Florianópolis (0.25) Joinville (0.17), Caxias do Sul e Blumenau (0.12), Londrina (0.11), que continuaram na mesma classificação do ano 2000. Já os municípios de Soledade, Turuçu e Porecatu (0.11) passaram de retardatários para em transição em 2010. Os demais municípios da Região Sul (1.179) foram classificados como retardatários, o que representou um aumento de $1.37 \%$ em comparação com o período anterior. Dentre esses municípios, os piores índices foram obtidos nos municípios de Aurora-SC, Lagoa Bonita do Sul-RS, Ampére-PR e Pinto Bandeira-RS, que apresentaram indicadores menores que 0.01 .

Dentre as variáveis utilizadas para a estimativa do indicador parcial econômico, identificou-se que os menores índices foram influenciados pelo baixo índice de emprego formal nos municípios, Produto Interno Bruto - PIB per capita municipal, valor adicionado e vitalidade da economia. Conforme apresentado na metodologia, tais variáveis visam a medir a situação econômica de cada município. Dessa 
forma, com o baixo índice de emprego formal e vitalidade econômica, pode-se inferir que os municípios da Região Sul estão passando por dificuldades quanto à geração de riquezas e capacidade do município em manter a atratividade econômica local, principalmente no Estado do Rio Grande do Sul, que apresentou os menores índices em todas as variáveis econômicas analisadas. 


\section{1 Indicador Social Parcial da Região Sul do Brasil}

A análise dos resultados do indicador social dos 1.191 municípios da Região Sul do Brasil demonstrou que, em 2000, havia dois municípios classificados em estágio avançado, Porto Alegre (1.32) e Joinville (0.57); 961 classificados como em transição e 228 em estágio retardatário. Dentre os municípios em transição, os melhores índices foram obtidos em Blumenau - SC (0.44), Florianópolis-SC (0.36), Jaraguá do Sul-SC (0.30), Itajaí-SC (0.26) e Chapecó-SC (0.24) e os menores foram identificados nos municípios de Tunas do Paraná - PR, Agudos do Sul-PR, Cruz Machado-PR, Paial-SC, São Miguel da Boa Vista-SC, Maçambara-RS, Matos Costa-SC e Herveiras-RS (0.10).

Em 2010, tal como ocorrido com o indicador econômico, houve redução no número de municípios classificados em estágio avançado, passando para apenas um município, sendo este Curitiba (0.62); do restante, 1.111 municípios classificados como em transição e 79 como retardatários. Os melhores índices dentre os classificados como em transição foram apresentados pelos municípios de Porto Alegre-RS (0.45), Joinville-SC (0.33), Florianópolis-SC (0.32), Blumenau-SC (0.28), Marau-RS (0.27) e Caxias do Sul-RS (0.26). E os piores índices foram identificados nos municípios de Santa Cruz de Monte Castelo-PR, Piçarras-SC, Lunardelli-PR, Santa Isabel do Ivaí-PR, Piraquara-PR, Pinto Bandeira e Colorado-PR (0.0003).

Frente a essa realidade, na Figura 2, foi apresentada a amostra da dispersão dos valores do indicador social dos municípios da Região Sul do Brasil, representada pelos 45 maiores índices sociais da Região durante os anos 2000 e 2010. De forma geral, o indicador da Região Sul do Brasil ficou assim classificado: em 2000 a Região possuía 0.16\% dos municípios em estágio avançado, $80 \%$, em transição, e $19 \%$ em estágio retardatário. Em 2010, o percentual de municípios em estágio avançado reduziu para $0.08 \%$. Houve ainda aumento dos municípios em transição para $93.3 \%$ e redução dos municípios retardatários para $6.5 \%$.

A análise dos resultados permitiu a identificação da média geral do indicador social nos estados da Região Sul do Brasil, em ambos os anos analisados, No ano 2000, o Estado do Paraná e de Santa Catarina apresentaram um indicador social médio igual a 0.09 e o Rio Grande do 
sul de 0.13 . No ano 2010, essa média se elevou passando para 0.15 no Paraná e em Santa Catarina e para 0.17 no Rio Grande do Sul.

A partir da análise da Figura 2, verificou-se que a linha de dispersão do ano 2010 se sobrepõe à linha do ano 2000, sendo mais evidente a perda do valor final do indicador social dos municípios de Joinville que passou de índice de 0.57 em 2000 para 0.33 em 2010, e Porto Alegre, que passou de 1.32 para 0.45 no mesmo período. Vale destacar que o Município de Curitiba-PR apresentou melhora significativa no valor do seu indicador, passando de em transição (0.16) para avançado (0.62), sendo este o único município nessa classificação em 2010. 
Figura 2. Amostra da dispersão dos valores do Indicador Social da Região Sul do Brasil - 2000 - 2010

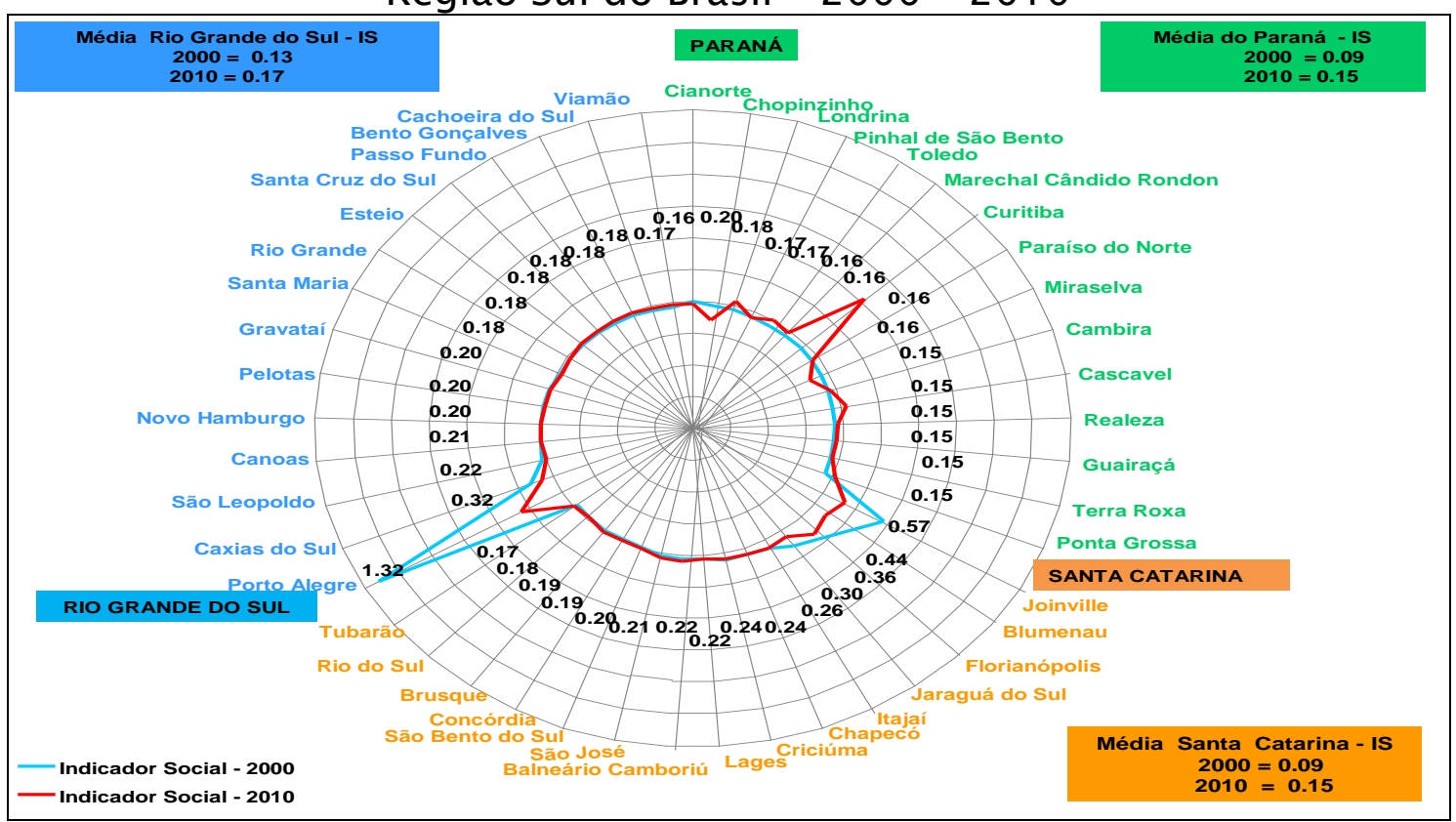

Fonte: Resultados da Pesquisa.

Os resultados classificatórios do indicador parcial social foram consequência do aumento/queda do índice de população rural, taxa de frequência escolar - ensino fundamental, despesas com assistência, previdência, educação e cultura, Índice de Desenvolvimento Humano Municipal - IDHM, queda da taxa de mortalidade infantil e baixo consumo de energia elétrica residencial.

\subsection{Indicador Ambiental Parcial da Região Sul do Brasil}

A análise dos resultados do indicador ambiental dos 1.191 municípios da Região Sul do Brasil durante os anos 2000 e 2010 demonstrou que, no ano 2000, a Região não possuía nenhum município classificado em estágio avançado, mas apresentou 1.187 municípios em estágio de transição e quatro em estágio retardatário. Dentre os classificados em estágio de transição, os melhores índices foram apresentados pelos municípios de Telêmaco Borba - PR e Sengés-PR (0.44), Timbó Grande-SC e Caçador-SC (0.42), São Cristóvão do Sul-SC (0.41), Guarapuava-PR e Ponta Grossa-PR (0.40), General Carneiro, Maringá-PR e Colombo-PR (0.39), Cascavel-PR (0.36), Toledo-PR e Foz do Iguaçu-PR (0.29). Os quatro municípios classificados em estágio 
retardatário foram: Nova Laranjeiras-PR (0.09), Pinto Bandeira-RS (0.001), Balneário Piçarras-SC (0.001) e Piçarras-SC (-0.03).

Em 2010, não houve nenhum município classificado em estágio avançado e apenas dois municípios em estágio retardatário, sendo eles: Pinto Bandeira (0.001) e Balneário Piçarras (-0.04). Os demais municípios da Região (1.189) foram classificados como em transição. Dentre esses, os melhores índices foram apresentados por: Telêmaco Borba - PR (0.43), Otacílio Costa-SC e Curitiba-PR (0.39), Calmon-SC, Monte Carlo-SC, Butiá-RS e Rio Negrinho-SC (0.36), Foz do Iguaçu-PR $(0.31)$.

Na Figura 3, apresentam-se os resultados do indicador parcial ambiental, da Região Sul do Brasil, durante os anos 2000 e 2010. Conforme a configuração dos dados na figura, os anos 2000 e 2010 apresentaram oscilações persistentes, embora, no ano 2010 , tenha sido evidenciada uma retração dos valores dos indicadores em comparação com o ano 2000. A análise dos dados demonstrou que o Estado do Paraná e Santa Catarina apresentaram um indicador ambiental médio de 0.27 em 2000 e de 0.28 em 2010. O Rio Grande do Sul, por sua vez, apresentou um índice ambiental médio de 0.26 em 2000 e de 0.29 em 2010.

Apesar da elevação média dos valores do indicador ambiental dos estados da Região Sul, esse resultado não foi o mesmo identificado na representação dos 45 municípios analisados nas Figuras 01 e 02, sendo que, na maioria dos casos, foi evidenciada uma linearidade no período analisado. Dessa forma, os melhores índices foram apresentados nos municípios de Curitiba-PR (0.62), Joinville - SC (0.57) e Porto Alegre - RS (1.32). Embora a tendência geral do indicador ambiental na Região Sul tenha sido de melhora, os 45 municípios analisados na Região apresentaram oscilações significativas no período analisado, principalmente no Estado do Paraná e Santa Catarina. Em síntese, durante o ano 2000, a Região Sul do Brasil não possuía municípios classificados em estágio avançado; $99.7 \%$ em estágio de transição e 0.25\% em estágio retardatário. Em 2010, novamente não houve municípios em estágio avançado, mas o percentual de municípios em estágio de transição elevou-se para $99.8 \%$ e os em estágio retardatário reduziram para $0.16 \%$, do total. Dessa forma, apesar de não existirem 
municípios em estágio avançado, houve melhora quanto ao número de municípios em transição e redução dos em estágio retardatário.

Figura 3. Amostra da dispersão dos valores do Indicador Ambiental da Região Sul do Brasil - 2000 - 2010

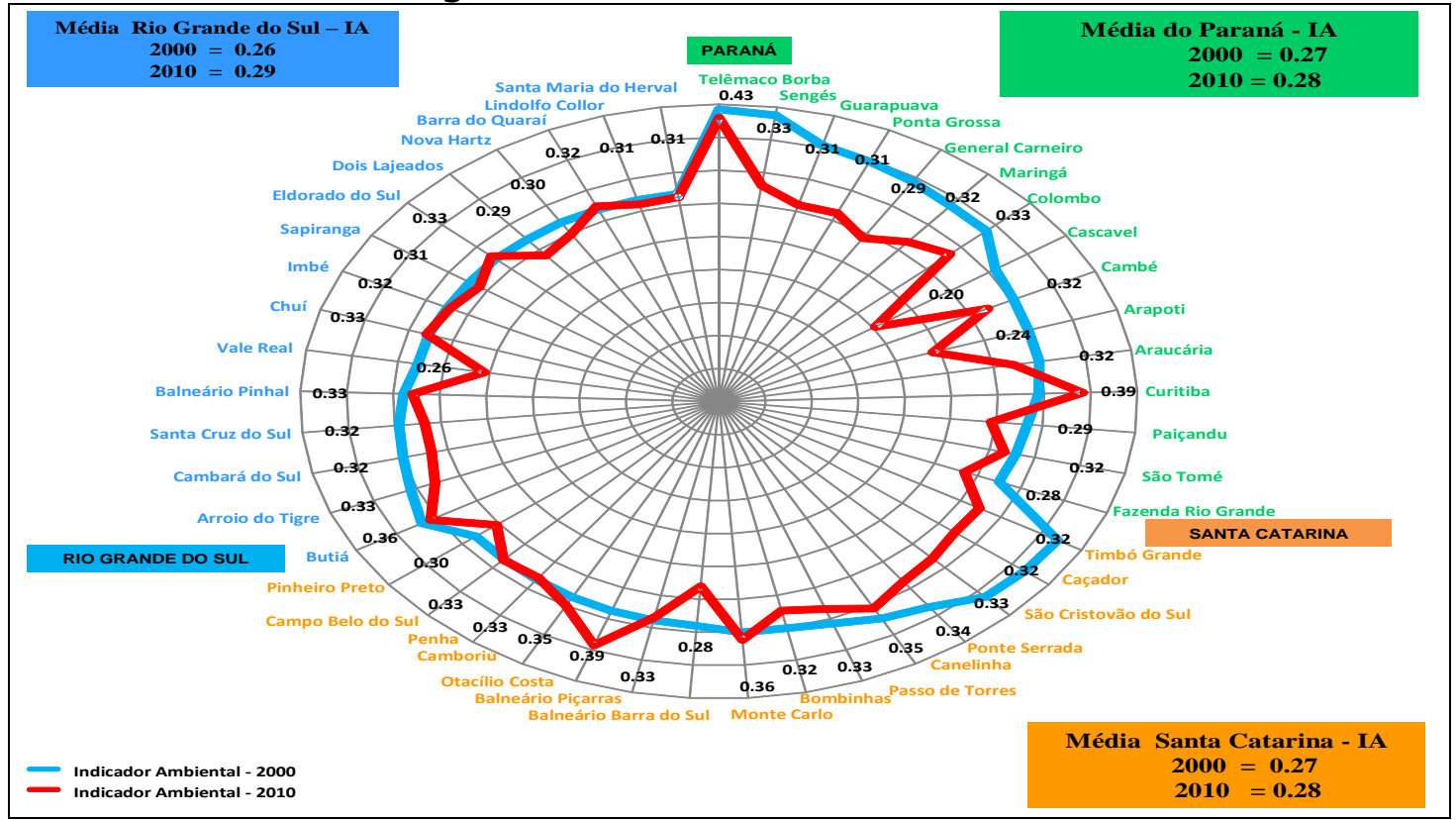

Fonte: Resultados da Pesquisa. 
A partir da avaliação das variáveis individuais que compõem o indicador ambiental parcial, identificou-se que as principais forças que possibilitaram melhor/pior desempenho do indicador ambiental durante os anos 2000 e 2010 foram exercidas pelo maior/menor índice de produção da silvicultura, baixo percentual de estabelecimentos com áreas de mata natural e artificial e área verde por habitante.

A partir da análise dos indicadores parciais que compõem o índice de desenvolvimento sustentável passa-se para a análise do IDRS, possibilitando a identificação e classificação dos municípios da Região Sul de acordo com as suas características individuais econômicas, sociais e ambientais, em avançado, transição e retardatário. Assim demonstrar-se o perfil de desenvolvimento sustentável da Região Sul do Brasil durante os anos 2000 e 2010 . Os resultados foram apresentados na seção 4.3 .

\subsection{O Indicador de Desenvolvimento Sustentável da Região Sul do Brasil}

A análise dos resultados do IDRS dos 1.191 municípios da Região Sul do Brasil demonstrou que, no ano 2000, havia apenas um município classificado em estágio avançado; 1.136 em estágio de transição e 54 em estágio retardatário. O único município em estágio avançado foi Porto Alegre (0.70). Os melhores índices dentre os classificados em transição foram apresentados pelos municípios de Joinville-SC (0.46), Curitiba-PR (0.42), Blumenau-SC (0.34) e Florianópolis-SC (0.29). Os três municípios mais representativos da Mesorregião Oeste do Paraná, Cascavel, Foz do Iguaçu e Toledo apresentaram valores de 0.19, 0.16 e 0.17 , respectivamente, ou seja, foram classificados como em transição. Os menores índices, mesmo que dentre os municípios em transição, foram identificados em Marquinho (0.07), Nova Laranjeiras, Santa Maria do Oeste (0.06), Pinto Bandeira-RS e Piçarras-SC (0.001).

Durante o ano 2010, a análise do IDRS apresentou apenas um município em estágio avançado - Curitiba-PR (0.54); 1.181 em estágio de transição e oito em estágio retardatário. Os melhores índices dentre os classificados como em transição foram obtidos nos municípios de Porto Alegre-RS (0.33), que passou de avançado em 2000 para em transição em 2010, Florianópolis-RS (0.28), Joinville-SC (0.27), Blumenau-RS e Maringá-SC (0.22), Caxias do Sul-RS, Itajaí-SC, 
Telêmaco Borba-PR, Londrina-PR, Balneário Camboriú-RS e Criciúma-SC (0.21). Os piores índices do IDRS foram obtidos nos municípios de Pinto Bandeira (0.001) e Piçarras (-0.01), consequentemente classificados como retardatários.

Dito isso, na Figura 4, apresenta-se o gráfico de dispersão do indicador de desenvolvimento sustentável da Região Sul do Brasil, durante os anos 2000 e 2010 . Conforme apresentado na figura, o seu diagrama de dispersão se apresenta de forma semelhante ao do apresentado no gráfico de dispersão do indicador social (Figura 2), demonstrando, assim, que possivelmente o resultado do IDRS foi influenciado pelos resultados obtidos no indicador social.

Cabe destacar que os melhores índices do IDRS no ano 2000 foram obtidos nos municípios de Curitiba-PR (0.42), Joinville-S (0.46) e Porto Alegre-RS (0.70). Tal como ocorrido com o indicador social, os municípios do Estado do Paraná apresentaram linearidade entre os valores do indicador econômico em 2000 e 2010, demonstrando leve retração entre os anos analisados, sendo que o melhor índice foi obtido no Município de Curitiba, com índice de 0.42 e 0.54, respectivamente. 0 Estado de Santa Catarina apresentou o Município de Joinville (0.46) com o melhor indicador social em 2000, mas, perdeu colocação para Florianópolis (0.28) em 2010. Os demais municípios do Estado apresentaram similaridade de valores, não apresentando grandes oscilações durante a análise. No Estado do Rio Grande do Sul, o melhor índice foi obtido no Município de Porto Alegre, em ambos os anos analisados. No entanto, verificou-se uma queda significativa, passando de 0.70 para 0.33 em 2010. Os demais municípios não apresentaram valores dispersos durante o período analisado.

Figura 4. Amostra da dispersão dos valores do IDRS da Região Sul do Brasil - $2000-2010$ 


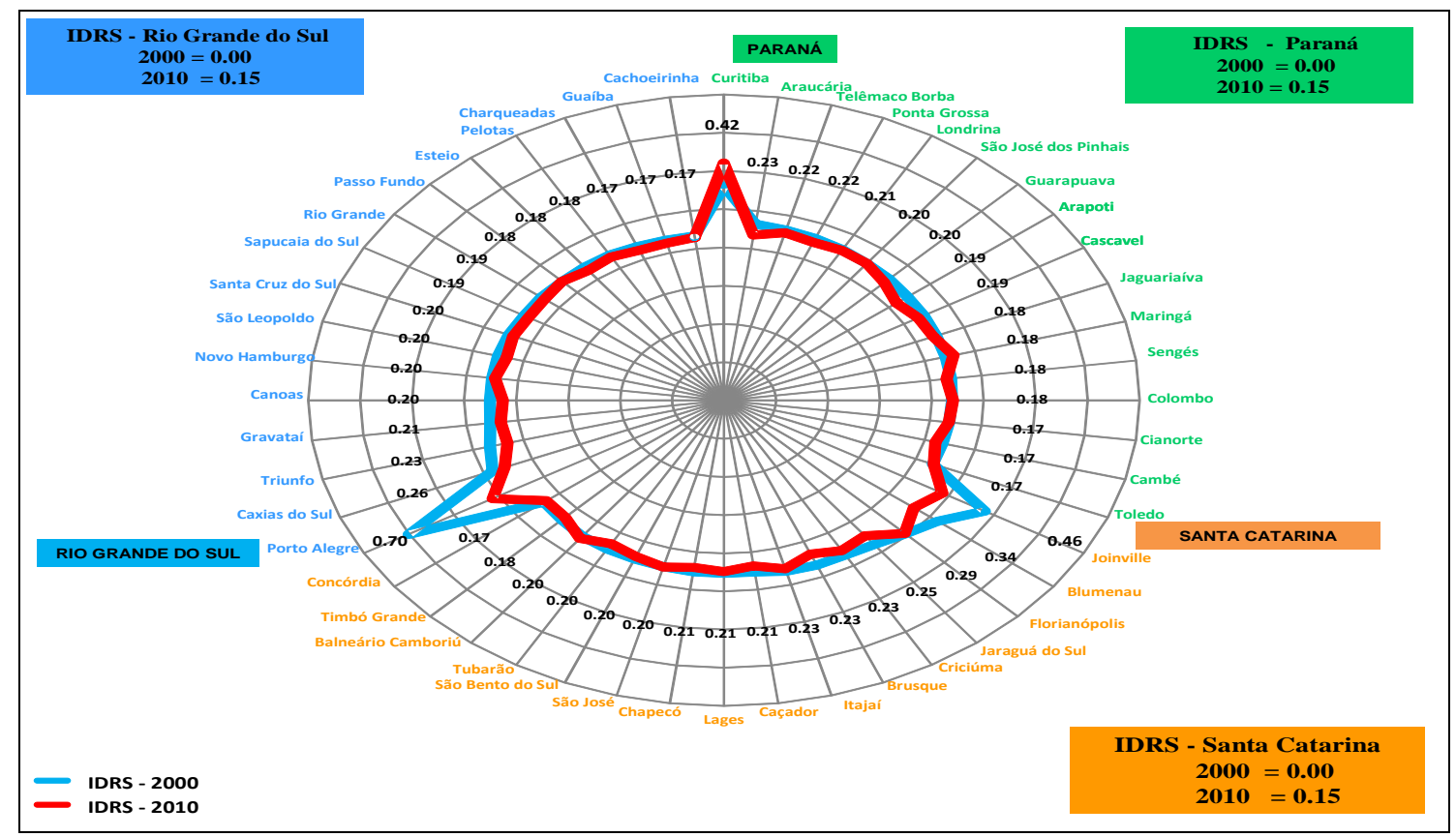

Fonte: Resultados da Pesquisa.

Identificou-se, na análise do IDRS que os piores resultados foram obtidos em alguns dos municípios localizados na Mesorregião CentroSul Paranaense, considerada uma das mesorregiões mais pobres do Estado do Paraná. Apesar dessa Mesorregião Centro-Sul apresentar uma das estruturas produtivas mais concentradas do estado, fortemente polarizada entre grandes e pequenas propriedades, concentrar $15 \%$ da cobertura florestal estadual remanescente e uma importante extensão de área reflorestada, ela ainda apresenta sérios problemas econômicos e sociais. Sua pequena base populacional e a baixa densidade de ocupação mantêm a mesorregião Centro-Sul como uma das regiões menos urbanizadas do Paraná. Tal característica é reforçada pelo fato da região concentrar $34 \%$ das famílias assentadas em projetos de reforma agrária e $62 \%$ das áreas indígenas do Paraná. A produção agrícola familiar é marcada por baixos rendimentos e a organização em cooperativas sofre sucessivas crises e todos os municípios dessa mesorregião apresentam IDHM abaixo da média paranaense, sendo o índice de renda per capita o que registra condições mais críticas. A dificuldade de geração de emprego na mesorregião reflete-se no fato de $1 / 3$ das famílias residentes encontrar-se em situação de pobreza (SESCPR, 2015; IPARDES, 2004).

Em síntese, o IDRS da Região Sul do Brasil, durante o ano 2000, apresentou $0.08 \%$ dos municípios classificados como em estágio 
avançado, $95.5 \%$ em transição e $4.45 \%$ em estágio retardatário. Em 2010, manteve-se o percentual de municípios em estágio avançado (0.08\%), mas houve uma significativa elevação no percentual de municípios em transição, passando para $99.2 \%$ e queda no número de municípios em estágio retardatário, passando para $0.67 \%$.

Estudos de Raiher e Ferrera de Lima (2014), por meio de uma análise comparativa, na qual, primeiramente fez-se o comparativo intrarregional, analisando a posição dos municípios da Região Sul do Brasil em relação à média desta região, no desempenho do IDHM; e, a segunda, a partir de um comparativo interregional, analisando os municípios da região Sul do Brasil em relação à média brasileira do IDHM, demonstrou que, no processo de desenvolvimento humano, as chances de se regredir são menores, especialmente pelo processo cumulativo. Esse mesmo fenômeno aconteceu com os município que se encontram no círculo vicioso, mas, neste caso, o processo cumulativo reforça os aspectos negativos, induzindo que os municípios depreciem cada vez mais o bem-estar de sua população, tal como o ocorrido com - IDRS da Região Sul em ambos os anos analisados, pois alguns dos municípios classificados como em estágio de transição e retardatário em 2000 se mantiveram nessa mesma classificação no ano 2010. Embora guardadas as proporções metodológicas nesta pesquisa, também verificou-se a manutenção dos municípios classificados em estágio retardatário, em transição e avançado, em ambos os períodos analisados.

Assim, ao analisar os resultados dos indicadores parciais econômicos, sociais e ambientais, identificou-se que estes indicadores causaram influência no resultado do IDRS, principalmente pelo aumento/redução do índice de emprego formal, consumo de energia elétrica setorial e vitalidade da economia, calculadas pelo indicador econômico; das variáveis consumo de energia residencial, despesas com saúde, educação, desporto, lazer, previdência e assistência, do indicador social e, pelas variáveis produção da silvicultura, estabelecimentos com áreas de matas naturais e artificiais e área verde por habitante, risco da moradia, do indicador ambiental, que proporcionaram a ordem de classificação dos municípios em maior/menor índice de desenvolvimento sustentável da Região Sul do 
Brasil, de acordo com o aumento/queda da participação de cada uma dessas variáveis analisadas, durante os anos 2000 e 2010.

\section{Conclusão}

A pesquisa contribui com uma análise do Desenvolvimento Regional Sustentável da Região Sul do Brasil, a partir da elaboração de um IDRS, que, além das variáveis econômicas e sociais, incorporou também variáveis ambientais.

Os indicadores sociais, econômicos, ambientais e sustentáveis foram aplicados nos 1.191 municípios da Região sul do Brasil, utilizando, no total, 30 variáveis, distribuídas igualmente entre os três índices parciais.

No indicador econômico parcial os resultados foram influenciados pelas variáveis: queda/elevação no índice do PIB per capita, valor adicionado, cota-parte do fundo de participação municipal e vitalidade da economia. Quanto ao indicador parcial social, identificou-se que este sofreu pressão do aumento/redução do índice de participação da população rural, taxa de frequência escolar - ensino fundamental, despesas com assistência, previdência, educação e cultura, IDHM, queda da taxa de mortalidade infantil e baixo consumo de energia elétrica residencial. Estas variáveis geraram índices baixos em cerca de $40 \%$ dos municípios do Estado do Paraná, em 34\% do Estado de Santa Catarina e em $40 \%$ dos municípios do Estado do Rio Grande do Sul, o que impactou negativamente no resultado final do indicador parcial social dos municípios da Região Sul, em ambos os anos analisados.

$O$ indicador ambiental parcial foi afetado pelo baixo percentual de produção da silvicultura, índice de estabelecimentos agropecuários com área de mata natural e artificial e baixo percentual de área verde por habitante. Embora a tendência geral do indicador ambiental na Região Sul tenha sido de melhora, foram evidenciadas oscilações significativas no período analisado, principalmente no Estado do Paraná e Santa Catarina. Em síntese, durante os períodos analisados não foram evidenciados municípios classificados em estágio avançado, 99.8\% ficaram classificados em estágio de transição e $0.16 \%$ em estágio retardatário. Dessa forma, apesar de não existirem municípios em 
estágio avançado, houve melhora quanto o número de municípios em transição e redução dos em estágio retardatário.

O conjunto de relações entre as variáveis econômicas, sociais e ambientais influenciou no resultado final do IDRS. Assim, as variáveis: emprego formal, consumo de energia elétrica setorial, consumo de energia residencial, despesas com saúde, educação, desporto, lazer, previdência e assistência, estabelecimentos com áreas de matas naturais e artificiais e área verde por habitante, risco da moradia impactaram diretamente na ordem de classificação dos municípios em maior/menor índice de desenvolvimento sustentável da Região Sul do Brasil, de acordo com o aumento/queda da participação de cada uma dessas variáveis analisadas, durante os anos 2000 e 2010. A melhora no desempenho desses indicadores representa um avanço na qualidade de vida da população, bem como no capital humano do estado.

De forma geral, a análise dos indicadores parciais econômicos, sociais e ambientais permitiu a classificação da Região Sul entre bom e regular, pois possuía, no ano 2000, em média de 69\% e, em 2010, 73.3\% dos seus municípios classificados como em transição, com potencial de elevação para avançado e a presença de alguns municípios tendendo ao estágio retardatário, pois não conseguiram alterar seu indicador ao longo dos anos analisados, caso de Piçarras-SC e Pinto Bandeira-RS. Assim os municípios classificados em estágio avançado possuem uma estrutura econômica favorável à geração de investimentos nos demais setores, alavancando a melhora das condições sociais e ambientais, e capacidade de melhora dos demais índices considerados na análise.

Embora tenha sido identificado que os estados ainda primem pela eficiência econômica seguida da social, em detrimento da qualidade da gestão ambiental dos seus municípios, uma vez que a gestão ambiental ainda seja vista de modo dissociado do ambiente econômico, é preciso levar em consideração que este não atua independentemente do sistema natural que lhe sustenta. Ao contrário, o sistema econômico interage com o meio ambiente, extraindo recursos naturais (componentes estruturais do capital natural) e energia e devolvendo resíduos. Dessa forma, uma correta gestão ambiental, seja na preservação de recursos, seja no tratamento e aproveitamento de resíduos, implica na possível 
evolução dos índices econômicos e sociais, já que está intrinsecamente ligada a todos os setores produtivos e entre as demandas sociais.

Diante disso, foi possível demonstrar quais são as possíveis limitações e potencialidades para o desenvolvimento sustentável da Região Sul do Brasil, pois, a partir da base metodológica utilizada, foi possível apontar os locais que necessitam de políticas públicas, visando o desenvolvimento econômico, social e/ou ambiental, para que a Região possa se desenvolver de forma sustentável e sustentada.

\section{REFERÊNCIAS}

ATLAS DE DESENVOLVIMENTO HUMANO NO BRASIL. Programa das Nações Unidas para o Desenvolvimento (PNUD). Disponível em: http://www.atlasbrasil.org.br/2013/. Acesso em: 20 de out. 2014.

FERRERA DE LIMA, J.; ALVES, L. R.; EBERHARDT, P.H.C.; DEL BIANCO, T. S.. Mensurar as Desigualdades Regionais no Brasil: Proposta Metodológica. In: V Seminário Internacional de Desenvolvimento Regional, 2011 , Santa Cruz do Sul. Anais... do V SIDR 2011. Santa Cruz do Sul: UNISC, vol. 01, p. 180-195, 2011.

GUALDA, N. L. O Índice de Desenvolvimento Regional como fator de identificação de polos de crescimento regionais - uma tentativa de identificação para a economia paranaense. In: // Encontro de Economia Paranaense, 2003, Maringá. Anais ... Maringá: TAC - Multimídia, p. 566583, 2003.

GUALDA, N. L. P.. IDR - Proposta Metodológica. Texto para Discussão. Programa de Mestrado em Economia - PME. Universidade Estadual de Maringá, 1995.

GUIMARÃES, R. P.; FEICHAS, S. A. Q. Desafios na Construção de Indicadores de Sustentabilidade. Ambiente \& Sociedade, Campinas (SP), v. XII, n. 2, p. 307-323, jul-dez. 2009.

INSTITUTO BRASILEIRO DE GEOGRAFIA E ESTATISTICA - IBGE. Censo Demográfico. Disponível em: <http://www.ibge.gov.br/home/>. Acesso em: 10 de out. 2014. 
IPARDES. Base de dados do Estado. Disponível em: <http://www.ipardes.gov.br/index.php>. Acesso em: 10 de out. 2014.

IPARDES. Leituras Regionais: Mesorregião Geográfica Centro-Sul Paranaense. Instituto Paranaense de Desenvolvimento Econômico e Social, 2004. Disponível em:

$<$ http://www.ipardes.gov.br/biblioteca/docs/leituras_reg_meso_centro_ sul.pdf $>$. Acesso em: 20 out. 2014.

IPEADATA. Base de dados. Disponível em: <http://www.ipeadata.gov.br/>. Acesso em: 5 de outubro. 2014.

MARTÍNEZ, R. Q. Indicadores de sustentabilidade: avanços e desafios para a América Latina. In.: ROMEIRO, A. R. (Org.). Avaliação e Contabilização de Impactos Ambientais. Campinas, SP: Editora da UNICAMP - Campinas (SP), p.252-270, 2004.

MOREJON, C. F. M.; FABRIS, C. S.; LAUFER, A. - O potencial dos resíduos da atividade doméstica do Brasil e sua relação com os créditos de carbono. Disponivel em: http://www.porthuseventos.com.br/site/eventos/2007/bioenergia/pt/tr abalhos/artigomorejon_et_al_unioeste-2007-c-i-bioenergia.doc. Acesso em: 20 de out. 2014.

OLIVEIRA, C. Desigualdades regionais no Rio Grande do Sul: um enfoque da nova geografia econômica. Revista Redes, Santa Cruz do Sul (RS), vol.10, n², p. 93-116, 2005.

PNUD, P. D. N. U. P. O. D. Atlas do Desenvolvimento Humano no Brasil, 2013a. Disponivel em: <http://www.atlasbrasil.org.br/2013/pt/consulta/>. Acesso em: $10 \mathrm{Jul}$. 2016.

RAIHER, A.P.; FERRERA DE LIMA, J. Desenvolvimento humano municipal no Sul do Brasil: evolução recente e o círculo vicioso da pobreza. Revista Acta Scientiarum. Human and Social Sciences, Maringa (PR), vol. 36, $\mathrm{n}^{\circ} 02, \mathrm{p} .147-154,2014$. 
RAIS - Relação Anual de Informações Sociais. Dados diversos. Portal do Emprego e do Trabalho. Disponível em: http://portal.mte.gov.br/rais/. Acesso 20 de out. 2014.

RODRIGUES, K.F., FERRERA DE LIMA, J. Índice de desenvolvimento regional sustentável: uma análise das mesorregiões do Estado do Paraná no período de 2002 a 2008. Revista Geografar, Curitiba (PR), vol.8, nº 1, p.175-202, 2013.

ROMEIRO, A. R. Avaliação e contabilização de impactos ambientais. Campinas (SP): Editora da UNICAMP, p. 10-29, 2004.

ROMEIRO, A. R. Introdução: economia ou economia política da sustentabilidade. In: MAY, Peter H.; LUSTOSA, M. C.; VINHA, V.. Economia do meio ambiente: teoria e pratica. 2. ed. Rio de Janeiro: Editora Campus, p. 3-14, 2003.

SACHS, I. Caminhos para o desenvolvimento sustentável. Rio de Janeiro (RJ): Garamond, p. 47-65, 2009.

SACHS, I . Desenvolvimento: includente, sustentável, sustentado. Rio de Janeiro (RJ): Garamond, p. 09-23, 2008.

SESC-PR - REGIÕES - INVENTARIO CULTURAL. Disponível em: http://www2.sescpr.com.br/inventario/regioes.php?cod=8. Acesso em: 20 out. 2014.

SICHE, R.; AGOSTINHO, E.; OTEGA, E.; ROMEIRO, A. Índices versus indicadores: precisões conceituais na discussão da sustentabilidade de países. Revista Ambiente \& Sociedade Campinas (SP), $\mathrm{n}^{\circ}$ 02, p. 137-148, 2007.

VEIGA, J.E. Indicadores socioambientais: evolução e perspectivas. Revista de Economia Política, São Paulo (SP), vol. 29, $\mathrm{n}^{\circ} 4$ (116), p 421-435, 2009. 
Aprovado em: 08/04/2016

\section{Sobre os autores}

Tatiani Sobrinho Del Bianco

Economista, Mestre e Doutoranda em Desenvolvimento Regional e Agronegócio UNIOESTE - Toledo-PR. Bolsista CAPES Toledo, PR, Brasil.

E-mail: tatiani.sdelbianco@gmail.com

\section{Jandir Ferrera de Lima}

Ph.D em Desenvolvimento Regional pela Université du Québec (UQAC) Bolsista e Pesquisador do Conselho Nacional de Desenvolvimento Científico e Tecnológico (CNPQ) e da Fundação Araucária (PR). Professor do Programa de Pós Graduação em Desenvolvimento Regional - UNIOESTE / Toledo, PR, Brasil. E-mail: jandir.lima@unioeste.br

\section{Camilo Freddy Mendoza Morejon}

Doutor em Engenharia Mecânica e Mestre em Engenharia Química pela Universidade Federal do Rio de Janeiro (COPPE/UFRJ). Professor associado da Universidade Estadual do Oeste do Paraná (UNIOESTE)/ Toledo - PR, Brasil. E-mail: camilo_freddy@hotmail.com 


\section{ANEXOS}

Quadro 1. Descrição do Indicador Parcial Econômico do Índice de Desenvolvimento Regional Sustentável (IDRS)

\begin{tabular}{|c|c|c|}
\hline Variável & Descrição & Fontes \\
\hline $\begin{array}{l}\text { Emprego Formal } \\
\text { - IEF }\end{array}$ & $\begin{array}{l}\text { Total de indivíduos empregados com carteira } \\
\text { assinada. Durante os anos } 2000 \text { e } 2010 \text {. Os } \\
\text { dados foram coletados a partir da relação de } \\
\text { vínculos ativos até } 31 / 12 \text { de cada ano analisado. }\end{array}$ & RAIS - TEM \\
\hline $\begin{array}{l}\text { Imposto de } \\
\text { Circulação de } \\
\text { Mercadorias e } \\
\text { Serviços - IICMS }\end{array}$ & $\begin{array}{l}\text { Total de impostos arrecadados sobre circulação } \\
\text { de mercadorias e prestação de serviços. Os } \\
\text { valores estão em moeda corrente do ano de } \\
2000 \text {, deflacionados pelo deflator implícito do } \\
\text { PIB nacional. Dado ponderado pelo total da } \\
\text { Receita Orçamentária do Estado. }\end{array}$ & IPEADATA \\
\hline $\begin{array}{lr}\text { Cota-Parte } & \text { do } \\
\text { Fundo } & \text { de } \\
\text { Participação dos } & \text { do } \\
\text { Municípios } & - \\
\text { IFPM } & \end{array}$ & $\begin{array}{l}\text { Verba repassada pelo governo estadual aos } \\
\text { municípios. A quantia é determinada pelo } \\
\text { número de habitantes do município. Os valores } \\
\text { estão em moeda corrente do ano de } 2000 \text {, } \\
\text { deflacionado pelo deflator implícito do PIB } \\
\text { nacional. }\end{array}$ & IPEADATA \\
\hline $\begin{array}{l}\text { Despesas } \\
\text { Orçamentarias } \\
\text { Totais - IDOT }\end{array}$ & $\begin{array}{l}\text { Valor das despesas orçamentarias municipais } \\
\text { totais durante os anos } 2000 \text { e } 2010 \text {. Os dados } \\
\text { foram ponderados pelo total de despesas } \\
\text { municipais. }\end{array}$ & IPEADATA \\
\hline $\begin{array}{l}\text { Consumo de } \\
\text { Energia Elétrica } \\
\text { Setorial-CES }\end{array}$ & $\begin{array}{l}\text { Total consumido em Mwh pelos setores } \\
\text { industrial, comercial e iluminação pública e } \\
\text { poderes públicos. A fonte dos dados é o } \\
\text { Ministério de Minas e Energia - MME } \\
\text { disponibilizado pelo IPEADATA. Os dados foram } \\
\text { ponderados pelo total consumido pelo Estado. }\end{array}$ & IPEADATA \\
\hline $\begin{array}{l}\text { Valor Adicionado } \\
\text { preços básicos - } \\
\text { IVA }\end{array}$ & $\begin{array}{l}\text { Valor Adicionado a preços correntes durante os } \\
\text { anos } 2000 \text { e } 2010 \text {. Os dados foram ponderados } \\
\text { pelo total do valor adicionado no município. }\end{array}$ & IPEADATA \\
\hline $\begin{array}{l}\text { Produto Interno } \\
\text { Bruto per capita } \\
\text { - IPIB per capita }\end{array}$ & $\begin{array}{l}\text { Soma do valor de tudo o que é produzido em } \\
\text { bens e serviços de um município dividido pela } \\
\text { população total do Estado, utilizados os valores } \\
\text { para os anos de } 2000 \text { e } 2010 \text {. }\end{array}$ & IPEDATA \\
\hline $\begin{array}{l}\text { Vitalidade da } \\
\text { Economia - IVEC }\end{array}$ & $\begin{array}{l}\text { Número de empresas abertas nos anos de } 1991 \text {, } \\
2000 \text { e } 2010 \text {, ponderadas em relação a seus } \\
\text { anos anteriores, formando o índice de vitalidade } \\
\text { da economia que demonstrará a capacidade de } \\
\text { manutenção da formalidade de cada município, } \\
\text { durante os anos } 2000 \text { e } 2010 \text {. }\end{array}$ & RAIS - TEM \\
\hline
\end{tabular}




\begin{tabular}{|l|l|l|}
\hline $\begin{array}{l}\text { Saldo Migratório } \\
\text { de Empregos }\end{array}$ & $\begin{array}{l}\text { Por falta de dados, utilizou-se os dados } \\
\text { referentes a Dez./2002 como proxy para o ano }\end{array}$ & RAIS - TEM \\
Formais - ISEF & $\begin{array}{l}\text { 2000. Para o ano } 2010 \text { os dados foram coletadas } \\
\text { formalmente, utilizando-se o número de } \\
\text { admitidos e demitidos em dez/2010. }\end{array}$ & \\
\hline $\begin{array}{l}\text { Receita } \\
\text { Orçamentaria } \\
\text { Total - IROT }\end{array}$ & $\begin{array}{l}\text { Valor das receitas orçamentarias municipais } \\
\text { totais durante os anos } 2000 \text { e 2010. Os dados } \\
\text { foram ponderados pelo total de despesas } \\
\text { municipais. }\end{array}$ & IPEADATA \\
\hline
\end{tabular}

Fonte: adaptado de Gualda (1995; 2003); Ferrera de Lima et al. (2011); Rodrigues e Ferrera de Lima (2013).

Quadro 2. Descrição do Indicador Parcial Social do Índice de Desenvolvimento Regional Sustentável (IDRS)

\begin{tabular}{|c|c|c|}
\hline Variável & Descrição & Fonte \\
\hline $\begin{array}{l}\text { População } \\
\text { Urbana - IPU }\end{array}$ & $\begin{array}{l}\text { População residente na área urbana. Os dados são } \\
\text { do Censo Demográfico para o ano } 2000 \text { e } 2010 \text {. O } \\
\text { Índice de análise foi ponderado pela população total } \\
\text { de cada município. }\end{array}$ & IBGE \\
\hline $\begin{array}{l}\text { População Rural } \\
\text { - IPR }\end{array}$ & $\begin{array}{l}\text { População residente na área rural. Os dados são do } \\
\text { Censo Demográfico para o ano } 2000 \text { e } 2010 \text {. O } \\
\text { Índice de análise foi ponderado pela população total } \\
\text { de cada município. }\end{array}$ & IBGE \\
\hline $\begin{array}{l}\text { Taxa de } \\
\text { Frequência } \\
\text { Escolar - Ensino } \\
\text { Fundamental - } \\
\text { ITEFEF }\end{array}$ & $\begin{array}{l}\text { Taxa de Frequência escolar dos alunos do ensino } \\
\text { fundamental. Os dados são do Atlas do } \\
\text { Desenvolvimento humano para os anos } 2000 \text { e } \\
2010 \text {, aba educação. }\end{array}$ & $\begin{array}{l}\text { Atlas do } \\
\text { Desenvolvi } \\
\text { mento } \\
\text { Humano - } \\
\text { PNUD }\end{array}$ \\
\hline $\begin{array}{l}\text { Consumo de } \\
\text { Energia Elétrica } \\
\text { Residencial - } \\
\text { ICER }\end{array}$ & $\begin{array}{l}\text { Total consumido em Mwh por consumidores que } \\
\text { utilizam a energia elétrica para fins residenciais. Os } \\
\text { dados foram coletados para os anos } 2000 \text { e } 2010 \text {. } \\
\text { Índice foi ponderado pelo número total de domicílios } \\
\text { do município. }\end{array}$ & IPEADATA \\
\hline $\begin{array}{lr}\text { Despesas rom } \\
\text { Saúde } & \text { e } \\
\text { Saneamento } & - \\
\text { IDSS } & \end{array}$ & $\begin{array}{l}\text { Despesas municipais com saúde e saneamento, } \\
\text { durante os anos } 2000 \text { e } 2010 \text {. Dados estes } \\
\text { ponderados pelo total de despesas de cada } \\
\text { município. }\end{array}$ & IPEDATA \\
\hline $\begin{array}{lr}\text { Despesas } & \text { com } \\
\text { Assistência } & \text { e } \\
\end{array}$ & $\begin{array}{l}\text { Despesas municipais com assistência e previdência, } \\
\text { durante os anos } 2000 \text { e } 2010 \text {. Dados estes }\end{array}$ & IPEADATA \\
\hline
\end{tabular}




\begin{tabular}{|c|c|c|}
\hline $\begin{array}{l}\text { Previdência - } \\
\text { IDAP }\end{array}$ & ponderados pelo total de despesas do Estado. & \\
\hline $\begin{array}{l}\text { Despesas com } \\
\text { Educação } \\
\text { Cultura-IDEC }\end{array}$ & $\begin{array}{l}\text { Despesas com ações voltadas para a área de } \\
\text { Educação e Cultura, durante os anos } 2000 \text { e } 2010 . \\
\text { Os valores estão em moeda corrente do ano de } \\
2000 \text {, deflacionado pelo deflator implícito do PIB } \\
\text { nacional. Dados estes ponderados pelo total de } \\
\text { despesas do Estado. }\end{array}$ & IPEADATA \\
\hline $\begin{array}{l}\text { Despesas com } \\
\text { Desporto } \\
\text { Lazer-IDDL }\end{array}$ & $\begin{array}{l}\text { Despesas com ações voltadas para a área de } \\
\text { Desporto e Lazer. Essa variável indica as melhorias } \\
\text { nas condições urbanas para garantir a saúde e } \\
\text { longevidade da população, durante os anos } 2000 \text { e } \\
2010 \text {. Dados estes ponderados pelo total de } \\
\text { despesas do Estado. }\end{array}$ & IPEADATA \\
\hline $\begin{array}{l}\text { Índice de } \\
\text { Mortalidade } \\
\text { Infantil - IIMF }\end{array}$ & $\begin{array}{l}\text { Percentual de mortalidade infantil nos municípios, } \\
\text { durante os anos } 2000 \text { e } 2010 \text {. Os dados foram } \\
\text { coletados no atlas de desenvolvimento humano do } \\
\text { PNUD. }\end{array}$ & $\begin{array}{l}\text { Atlas de } \\
\text { Desenvolvi } \\
\text { mento } \\
\text { Humano - } \\
\text { PNUD }\end{array}$ \\
\hline $\begin{array}{l}\text { Índice de } \\
\text { Desenvolviment } \\
\text { o Humano } \\
\text { Municipal - } \\
\text { IIDHM }\end{array}$ & $\begin{array}{l}\text { Índice de desenvolvimento humano total dos } \\
\text { municípios, durante os anos } 2000 \text { e } 2010 \text {. Os dados } \\
\text { foram coletados no atlas de desenvolvimento } \\
\text { humano do PNUD. }\end{array}$ & $\begin{array}{l}\text { Atlas de } \\
\text { Desenvolvi } \\
\text { mento } \\
\text { Humano - } \\
\text { PNUD }\end{array}$ \\
\hline
\end{tabular}

Fonte: adaptado de Gualda (1995; 2003); Ferrera de Lima et al. (2011); Rodrigues e Ferrera de Lima (2013).

Quadro 3. Descrição do Indicador Parcial Ambiental do Índice de Desenvolvimento Regional Sustentável (IDRS)

\begin{tabular}{|l|l|c|}
\hline \multicolumn{1}{|c|}{ Variável } & \multicolumn{1}{|c|}{ Descrição } & Fonte \\
\hline Silvicultura - IS & $\begin{array}{l}\text { Valor da Silvicultura total municipal (mil/Reais) } \\
\text { durante os anos 2000 e 2010. Os dados foram } \\
\text { ponderados pelo total produzido no Estado, no } \\
\text { período analisado. }\end{array}$ & IBGE \\
\hline $\begin{array}{l}\text { Índice de } \\
\text { estabelecimentos } \\
\text { com florestas e } \\
\text { matas naturais e }\end{array}$ & $\begin{array}{l}\text { O Índice dos estabelecimentos com áreas de mata } \\
\text { naturais e artificiais foi elaborado a partir dos dados } \\
\text { de dados atualizados este índice foi utilizado como }\end{array}$ & IBGE \\
\hline
\end{tabular}




\begin{tabular}{|c|c|c|}
\hline artificiais - IEFM & $\begin{array}{l}\text { proxy para os anos } 2000 \text { e } 2010 \text {. Os dados foram } \\
\text { ponderados pelo numero de estabelecimentos com } \\
\text { áreas de matas naturais e artificiais pela área } \\
\text { (hectares) total municipal. }\end{array}$ & \\
\hline $\begin{array}{l}\text { Índice de } \\
\text { Poluição Hídrica - } \\
\text { IIPH }\end{array}$ & $\begin{array}{l}\text { O Índice poluição hídrica foi baseado no total de } \\
\text { domicílios municipais com poluição hídrica de algum } \\
\text { tipo no momento da capitação. Os dados foram } \\
\text { ponderados pelo total de domicílios do Estado com } \\
\text { algum tipo de poluição. Os dados são referentes } \\
\text { anos } 2000 \text { e } 2010 \text {. }\end{array}$ & IBGE \\
\hline $\begin{array}{l}\text { Domicílios com } \\
\text { atendimento de } \\
\text { água encanada - } \\
\text { IIAE }\end{array}$ & $\begin{array}{l}\text { Número de domicílios com atendimento de água } \\
\text { encanada nos municípios nos anos } 2000 \text { e } 2010 \text {. Os } \\
\text { dados foram ponderados pelo total de domicílios } \\
\text { com água encanada do Estado. }\end{array}$ & IBGE \\
\hline $\begin{array}{l}\text { Domicílios com } \\
\text { água encanada e } \\
\text { banheiro - IIAEB }\end{array}$ & $\begin{array}{l}\text { Número de domicílios com atendimento de água } \\
\text { encanada e banheiro com saneamento básico nos } \\
\text { municípios nos anos } 2000 \text { e } 2010 \text {. Os dados foram } \\
\text { ponderados pelo total de domicílios com água } \\
\text { encanada e banheiro do Estado. }\end{array}$ & IBGE \\
\hline $\begin{array}{l}\text { Densidade } \\
\text { demográfica } \\
\text { domiciliar -IDDD }\end{array}$ & $\begin{array}{l}\text { Percentual da população em domicílios com } \\
\text { densidade }>2 \text { durante os anos } 2000 \text { e } 2010 \text {. Os } \\
\text { dados foram coletados e mantidos de acordo com os } \\
\text { percentuais do banco de dados original. }\end{array}$ & $\begin{array}{l}\text { Atlas de } \\
\text { Desenvolvi } \\
\text { mento } \\
\text { Humano - } \\
\text { PNUD }\end{array}$ \\
\hline $\begin{array}{l}\text { Risco das } \\
\text { Moradias }\end{array}$ & $\begin{array}{l}\text { Contempla o número de domicílios de forma } \\
\text { inadequada (incluí os domicílios particulares } \\
\text { permanentes com abastecimento de água } \\
\text { proveniente de poço ou nascente ou outra forma, } \\
\text { sem banheiro e sanitário ou com escoadouro ligado } \\
\text { à fossa rudimentar, ou descarte direto em solo e lixo } \\
\text { queimado, enterrado ou jogado em terreno baldio } \\
\text { ou logradouro, em rio, lago ou mar ou outro destino } \\
\text { e mais de } 2 \text { moradores por dormitório.), ponderado } \\
\text { pelo total de domicílios totais de forma inadequada } \\
\text { no Estado. }\end{array}$ & IBGE \\
\hline $\begin{array}{l}\text { Percentual de } \\
\text { domicílios com } \\
\text { coleta de Lixo - } \\
\text { IIDCL }\end{array}$ & $\begin{array}{l}\text { Percentual da população em domicílios com coleta } \\
\text { de lixo, durante os anos } 2000 \text { e } 2010 \text {. Os dados } \\
\text { foram coletados e mantidos de acordo com os } \\
\text { percentuais do banco de dados original. }\end{array}$ & $\begin{array}{l}\text { Atlas de } \\
\text { Desenvolvi } \\
\text { mento } \\
\text { Humano - } \\
\text { PNUD }\end{array}$ \\
\hline $\begin{array}{l}\text { Área Verde por } \\
\text { habitante - IIAV }\end{array}$ & $\begin{array}{l}\text { O índice área verde foi calculado com base no total } \\
\text { de área de mata natural e artificial ponderado pelo } \\
\text { total da população municipal. Os dados dos censos } \\
\text { agropecuários de } 1995 \text { e } 2006 \text {. Por falta de dados }\end{array}$ & IBGE \\
\hline
\end{tabular}




\begin{tabular}{|c|c|c|}
\hline & $\begin{array}{l}\text { atualizados este índice foi utilizado como proxy para } \\
\text { os anos } 2000 \text { e } 2010\end{array}$ & \\
\hline $\begin{array}{l}\text { Estimativa da } \\
\text { Geração de RSU - } \\
\text { IGRSU }\end{array}$ & $\begin{array}{l}\text { A estimativa do potencial de geração de RSU é } \\
\text { obtida a partir da multiplicação entre a população } \\
\text { municipal total e a geração média de RSU municipal, } \\
\text { com base na metodologia de Morejon et al. (2007). }\end{array}$ & IBGE \\
\hline
\end{tabular}

Fonte: adaptado de Gualda (1995; 2003); Ferrera de Lima et al. (2011); Rodrigues e Ferrera de Lima (2013). 